\title{
HUBUNGAN ANTARA INDEKS MASSA TUBUH DENGAN KADAR LDL PADA PENDERITA DIABETES MELITUS TIPE II FKTP DI PRAKTEK MANDIRI DOKTER HAKIKIYAH LAMPUNG TENGAH TAHUN 2019
}

\author{
Firhat Esfandiari ${ }^{1}$, Selvia Anggraeni ${ }^{2}$, Muhammad Nur ${ }^{3}$, Fathurrizqi Al-Faiz \\ Santoso ${ }^{4}$

\begin{abstract}
${ }^{1}$ Departemen Penyakit Dalam Rumah Sakit Natar Medika Bandar Lampung
${ }^{2}$ Departemen Biologi Medik Fakultas Kedokteran Universitas Malahayati

${ }^{3}$ Departemen Patologi Klinik Fakultas Kedokteran RSUD Pringsewu

${ }^{4}$ Prodi Kedokteran Umum FK Universitas Malahayati
\end{abstract}

\begin{abstract}
The Relationship Of Body Mass Index With LDL Levels In Patients With Tipe II Diabetes Mellitus FKTP In The Independent Practice Of Doctor Of Central Lampung Tengah Hakikiyah 2019. Obesity or excessive weight loss associated with the risk of incident Diabetes Mellitus. One simple way is commonly used to determine obesity is by measuring Body Mass Index (BMI). To determine the relationship of Body Mass Index with LDL levels in patients with Type II FKTP Diabetes Mellitus in Independent Practice Hakikiyah Central Lampung in 2019. This type of research is Observational Analytic research with Cross-Sectional study design. The data used are sekunder data records medic in Independent Practice Physicians Hakikiyah. Analysis of the relationship is done by using Chi-square test. Obtained from respondents who had normal LDL levels were 21 respondents $(61.8 \%)$ and obtained with excessive LDL levels, there were 13 respondents $38.2 \%$. While in the obese group who had normal LDL level is 9 respondents $32.0 \%$, and in obesity group that contained excessive levels of LDL her 17 respondents $68.0 \%$. There is a relationship between Body Mass Index with LDL levels in patients with Type II Diabetes Mellitus. It was proven that there was a relathionship with $\mathrm{p}<0,024$ test by chi-square. Which means that there is a significance between Body Mass Index and LDL levels .
\end{abstract}

Keywords : Body mass index, LDL, Type II Diabetes Mellitus

\begin{abstract}
Abstrak: Hubungan Indeks Massa Tubuh Dengan Kadar LDL Pada Penderitta Diabetes Melitus Tipe II FKTP Di Praktek Mandiri Dokter Hakikiyah Lampung Tengah 2019. Obesitas atau berat badan yang berlebih berhubungan dengan risiko kejadian Diabetes Melitus. Salah satu cara sederhana yang umum digunakan untuk menentukan obesitas adalah dengan pengukuran Indeks Massa Tubuh (IMT). Untuk mengetahui hubungan Indeks Massa Tubuh dengan kadar LDL pada pasien Diabetes Melitus Tipe II FKTP di Praktek Mandiri Hakikiyah Lampung Tengah Tahun 2019. Jenis penelitian yang digunakan adalah penelitian Analitik Observasional dengan rancangan studi Cross-Sectional. Data yang digunakan adalah data sekunder dengan data rekam medis yang ada di Praktek Mandiri Dokter Hakikiyah. Analisis hubungan dilakukan dengan menggunakan uji Chi-Square. Responden dengan kadar LDL normal 21 responden $61,8 \%$ dan kadar LDL yang berlebih terdapat 13 responden 38,2\%. Pada kelompok obesitas yang kadar LDL normal 9 reponden $32,0 \%$, dan pada kelompok obesitas kadar LDL berlebih terdapat 17 responden $68,0 \%$. Terdapat hubungan antara Indeks Massa Tubuh dengan kadar LDL pada penderita Diabetes Melitus Tipe II. Orang yang memiliki Indeks Massa Tubuh yang berlebih 3.443 kali lebih berisiko untuk meningkatkan kadar LDL dan mengakibatkan terjadinya faktor risiko Diabetes Melitus dibandingkan dengan orang yang Indeks Massa Tubuhnya yang normal.
\end{abstract}

Kata Kunci : Indeks massa tubuh, Kadar LDL, Diabetes Melitus Tipe II. 


\section{PENDAHULUAN}

Diabetes Melitus (DM) merupakan penyakit kronis dikarenakan sekresi insulin endogen yang tidak efektif. Diabetes Melitus diklasifikasikan menjadi diabetes melitus tipe I Insulin Dependen Diabetes Melitus (IDDM) dan diabetes melitus tipe II disebut NonDependen insulin Diabetes Melitus (NDIDM) (Longmore dkk, 2014).

Pada pasien DM Tipe 2 dapat ditemukan kelainan metabolisme lipid berupa dislipidemia. Dislipidemia adalah kelainan pada metabolisme lipid yang ditandai dengan adanya peningkatan atau penurunan fraksi lipid dalam plasma. Kelainan fraksi lipid yang utama meliputi kenaikan kolesterol total, trigliserida, Low Density Lipoprotein (LDL), dan penurunan High Density Lipoprotein (HDL). Dislipidemia yang diakibatkan oleh DM merupakan dislipide Obesitas terutama yang bersifat sentral merupakan salah satu faktor yang mempengaruhi timbulnya penyakit DM Tipe 2. Timbunan lemak yang berlebihan di dalam tubuh dapat mengakibatkan resistensi insulin yang berpengaruh terhadap kadar gula darah penderita diabetes melitus (Waspadji, 2004).

Diabetes melitus adalah penyakit gangguan metabolik dengan ciri ditemukan konsentrasi glukosa yang tinggi di dalam darah (hiperglikemia) (Longmore dkk, 2014).

Penyakit ini ditandai dengan munculnya gejala khas yaitu poliphagia, polidipsia dan poliuria serta sebagian mengalami kehilangan berat badan. DM merupakan penyakit kronis yang sangat perlu diperhatikan dengan serius. DM yang tidak terkontrol dapat menyebabkan beberapa komplikasi seperti kerusakan mata, ginjal pembuluh darah, saraf dan jantung. Penyakit DM biasanya ditandai dengan poliuri (banyak kencing), polidipsi (banyak minum) dan polifagi (banyak makan), serta peningkatan kadar glukosa darah atau hiperglikemia (glukosa puasa $\geq 126 \mathrm{mg} / \mathrm{dL}$ atau postprandial $\geq 200 \mathrm{mg} / \mathrm{dL}$ atau glukosa sewaktu $\geq 200 \mathrm{mg} / \mathrm{dL}$ ). Keadaan hiperglikemia ini timbul ketika tubuh tidak dapat memproduksi insulin secara normal atau insulin tidak dapat bekerja secara efektif (WHO, 2017).

Insulin merupakan hormon yang dihasilkan oleh pankreas dan berfungsi untuk mengangkut glukosa dari makanan ke dalam sel yang selanjutnya akan diubah menjadi energi guna memenuhi kebutuhan otot dan jaringan dalam menjalankan fungsinya. Seseorang yang terkena DM tidak dapat menggunakan glukosa secara normal, sehingga glukosa akan tetap beradapada sirkulasi darah yang akan merusak jaringan baik secara akut maupun kronik (IDF, 2015).

Prevalensi penderita DM di seluruh dunia sangat tinggi dan cenderung meningkat setiap tahun. Jumlah penderita DM di seluruh dunia mencapai 422 juta penderita pada tahun 2014. Jumlah penderita tersebut jauh meningkat dari tahun 1980 yang hanya 180 juta penderita. Jumlah penderita DM yang tinggi terdapat di wilayah South-East Asia dan Western Pacific yang jumlahnya mencapai setengahdari jumlah seluruh penderita DM di seluruh dunia. Satu dari sebelas penduduk adalah penderita DM dan 3,7 juta kematian disebabkan oleh DM maupun komplikasi dari DM (WHO, 2017).

Penderita DM di Indonesia berdasarkan data dari IDF pada tahun 2014 berjumlah 9,1 juta atau 5,7 \% dari total penduduk. Jumlah tersebut hanya untuk penderita DM yang telah terdiagnosis dan masih banyak penderita DM yang belum terdiagnosis. Indonesia merupakan negara peringkat ke-5 dengan jumlah penderita DM terbanyak pada tahun 2014. Indonesia pada tahun 2013 berada diperingkat ke-7 penderita DM terbanyak di dunia dengan jumlah penderita 7,6 juta (Perkeni, 2015). 
METODE

Penelitian ini merupakan penelitian analitik observasional, yaitu dengan melihat data sekunder indeks massa tubuh responden dengan kadar LDL. Teknik sampel yang digunakan adalah total sampling. Penelitian ini dilaksanakan pada bulan November 2019. Populasi dalam penelitian ini adalah pasien di praktek mandiri Dokter Hakikiyah Lampung Tengah 2019. Pada Penelitian ini adalah sampel yang diambil seluruh pasien yang berobat di dalam klinik selama dalam pengobatan.

Data yang diambil hanya data yang memenuhi kriteria inklusi (1) bersedia mengikuti penelitian, pasien penderita diabetes melitus tipe 2 , (3) usia berada pada rentang lebih dari 18 tahun, (4) memiliki IMT pada

\section{HASIL}

Subjek penelitian ini terdiri dari 59 responden terdiri dari laki-laki dan wanita, laki- laki terdapat 27 pasien dan wanita terdapat 32 pasien. Semua rentang normoweight - over weight. Kriteria eksklusi pada penelitian ini yaitu (1) pasien yang sedang mengkonsumsi obat anti kolesterol, (2) pasien diabetes melitus yang menggunakan insulin (ketergantungan insulin), (3) pasien yang merokok, (4) pasien yang mengkonsumsi minuman yang beralkohol.

Teknik analisis data pada penelitian analitik observasional ini menggunakan uji univariat dan bivariate (Notoatmodjo, 2012). Data yang diperoleh dari analisa dengan SPSS menggunakan uji univariat dan bivariat data yang akan dicari distribusi frekuensinya lalu mencari adakah hubungan antara dua varibel tersebut dan dijelaskan hasilnya secara deskriptif.

responden ini memiliki kriteria eksklusi dan inklusi sehingga bisa dilakukan olah data. Hasil yang diperoleh dapat dilihat dari tabel dibawah ini :

\section{Distribusi Frekuensi Indeks Massa Tubuh Dengan Kadar LDL}

Tabel 1. Distribusi Frekuensi Hubungan Indeks Massa Tubuh Dengan Kadar LDL

\begin{tabular}{cccc}
\hline Variabel & Kategori & Frekuensi & Persentase \\
\hline \multirow{2}{*}{ IMT } & Obesitas & 34 & 57.6 \\
\cline { 2 - 4 } Kadar LDL & Tidak Obesitas & 25 & 42.4 \\
\cline { 2 - 4 } & Normal & 29 & 49.2 \\
\cline { 2 - 4 } & Tidak normal & 30 & 50.8 \\
\hline
\end{tabular}

Diatas dapat dilihat tabel distribusi frekuensi indeks massa tubuh bahwa dari 59 subyek penelitian berdasarkan indeks massa tubuh di dapatkan bahwa yang memiliki indeks massa tubuhnya berlebih sebanyak 25 responden $42,4 \%$ dan yang memiliki indeks massa tubuhnya normal atau nilai indeks massa tubuhnya 18,5 24,9 sebanyak 34 responden $57 \%$. Dengan demikian indeks massa tubuh pada pasien diabetes melitus tipe II lebih banyak yang memiliki indeks massa tubuhnya normal dibandingkan dengan yang indeks massa tubuh yang berlebih $>25$.

Dan juga dapat dilihat pada tabel distribusi frekuensi kadar LDL kelompok kadar LDL berdasarkan tabel diatas dapat dilihat bahwa dari 59 subyek penelitian berdasarkan kadar LDL pada penderita diabetes melitus tipe II di dapatkan bahwa kadar LD yang berlebih atau kadarnya >200 adalah 30 
responden $50,8 \%$ dan yang memiliki kadarnya lebih rendah atau dikatakan normal <200 adalah 29 responden $49,2 \%$. Dengan demikian kadar LDL pada pasien diabetes melitus tipe II memiliki kadar yang berlebih itu lebih banyak dibandingkan kadar LDL yang normal atau yang kadarnya kurang dari $<200$. Status gizi memiliki pengaruh terhadap kejadian diabetes melitus tipe
II. Indeks massa tubuh tinggi mempunyai resiko 2 kali lebih besar untuk terkena diabetes melitus tipe II dibandingkan dengan indeks massa tubuh rendah. Hasil penelitian menunjukkan bahwa obesitas umum berisiko 2,24 kali sedangkan obesitas abdominal berisiko 2,44 kali untuk terjadinya diabetes melitus tipe II (Koampa dkk, 2016).

\section{Hubungan Indeks Massa Tubuh Dengan Kadar LDL}

Tabel 2. Hubungan Indeks Massa Tubuh Dengan Kadar LDL Pada Penderita Diabetes Melitus Tipe 2 FKTP di Praktek Mandiri Dokter Hakikiyah Lampung Tengah 2019

\begin{tabular}{ccccccc}
\hline \multirow{2}{*}{ IMT } & \multicolumn{2}{c}{ Kadar LDL } & \multicolumn{2}{c}{ Jumlah } & $\begin{array}{c}\text { P- } \\
\text { Value }\end{array}$ & CI ( 95\%) \\
\cline { 2 - 5 } & Normal & $\begin{array}{c}\text { Tidak } \\
\text { Normal }\end{array}$ & $\mathbf{N}$ & $\%$ & \% & \\
\hline Normal & 21 & 13 & 34 & $100 \%$ & & 3,433 \\
$\begin{array}{c}\text { Tidak } \\
\text { Normal }\end{array}$ & 8 & 17 & 25 & $100 \%$ & 0,024 & $(1.156-$ \\
Total & 29 & 30 & 59 & 100 & & \\
\hline
\end{tabular}

Analisis hubungan antara indeks massa tubuh dengan kadar LDL pada penderita diabetes melitus tipe II FKTP di Lampung Tengah Tahun 2019. Bahwa dari 59 responden terdapat 21 orang $61,8 \%$ dengan kadar LDL normal $<200 \mathrm{mg} / \mathrm{dL}$ dan 13 orang ( $38,2 \%)$ dengan kadar LDL $>200 \mathrm{mg} / \mathrm{dL}$. Sedangkan pada kelompok obesitas yang kadar LDL nya normal $<200$ $\mathrm{mg} / \mathrm{dL}$ adalah 8 orang $32,0 \%$ dan pada kelompok obesitas yang kadar LDL nya berlebih atau $>200 \mathrm{mg} / \mathrm{dL}$ terdapat 17 orang 68,0. Hasil uji Chi Square didapat nilai $p>a \quad 0,024<0,05$ yang artinya disimpulkan secara statistik terdapat kemaknaan antara indeks massa tubuh dengan kadar LDL pada penderita diabetes melitus tipe II. Dan $\mathrm{OR}=3,433$ yang artinya pada penderita diabetes melitus tipe 2 terdapat risiko 3 kali meningkat pada kadar LDL nya tersebut.

\section{PEMBAHASAN}

Pada pasien diabetes melitus tipe II dapat ditemukan kelainan metabolisme lipid berupa dislipidemia. Dislipidemia adalah kelainan pada metabolisme lipid yang ditandai dengan adanya peningkatan atau penurunan fraksi lipid dalam plasma. Kelainan fraksi lipid yang utama meliputi kenaikan kolesterol total, trigliserida, Low Density Lipoprotein (LDL), dan penurunan High Density Lipoprotein (HDL). Dislipidemia yang diakibatkan oleh Diabetes Melitus merupakan dislipidemia sekunder (Koampa dkk, 2016).

Pada penelitian sebelumnya menurut Koampa,dkk (2016) tidak terdapat hubungan yang signifikan antara indeks massa tubuh dengan profil lipid pada pasien DM Tipe 2 di RSUP Prof. Dr. R. D. Kandou Manado dengan $p=0,045$. Hal ini dapat disebabkan karena pada penelitian ini sebagian besar pasien telah menjalani pengobatan sehingga telah terjadi perubahan terhadap kadar profil lipid. Indeks massa tubuh tinggi mempunyai 
resiko 2 kali lebih besar untuk terkena diabetes melitus tipe II dibandingkan dengan indeks massa tubuh rendah. Hasil penelitian menunjukkan bahwa obesitas umum berisiko 2,24 kali sedangkan obesitas abdominal berisiko 2,44 kali untuk terjadinya diabetes melitus tipe II (Koampa dkk, 2016).

Pada penelitian Husain,dkk (2016) menunjukkan hasil peningkatan kadar LDL pada pasien laki-laki dan perempuan pada penderita diabetes melitus tipe II. Tetapi penelitian ini menunjukkan bahwa indeks massa tubuh memiliki korelasi negatif bahwa dari uji korelasi sendiri didapatkan untuk kadar LDL memiliki nilai sebesar $p=0,721$ hasil yang didapatkan tidak mengungkapkan korelasi dengan indeks massa tubuh. Berbeda dari penelitian serupa lainnya Hasil studi yang dilakukan di Korea dijelaskan bahwa ada korelasi positif antara indeks massa tubuh dengan LDL-C (Husain dkk, 2016).

Temuan ini disebabkan oleh peningkatan sekresi LDL-C oleh hati dan penghapusan lambat dari TG lipoprotein kaya, serta peningkatan kadar substrat untuk produksi TG dari mobilisasi augmented asam lemak bebas (FFA) dari jaringan adiposa pada orang dengan diabetes melitus. Temuan ini dianggap karena perbedaan genetik, perbedaan dalam gaya hidup dan pengelolaan populasi spesifik diabetes melitus sedang dipelajari. Dalam penelitian ini pasien diabetes melitus tipe II dengan indeks massa tubuh yang normal jika dibandingkan dengan obesitas tidak menunjukkan perbedaan yang signifikan dalam nilai LDL kecuali HDL ( Husain dkk, 2016).

Pada penelitian Hasan dkk (2013) menunjukkan hasil peningkatan kadar LDL dan penurunan kadar HDL memiliki korelasi yang kuat terhadap kejadian diabetes melitus untuk kadar LDL memiliki nilai sebesar $p=0,001$. Berdasarkan nilai $(p<0,05)$, menunjukkan adanya suatu hubungan antara indeks massa tubuh dengan peningkatan kadar LDL. Dan terdapat beberapa penelitian yang pernah dilakukan yang berkaitan dengan ketidakseimbangan kadar LDL (Hasan dkk, 2013).

Pada penelitian Sukatemin (2013) diperoleh hubungan yang signifikan antara indeks massa tubuh dengan peningkatan $L D L$, dengan nilai kemaknaan sebesar 0,011. Selain itu, berdasarkan uji regresi, indeks massa tubuh merupakan variabel yang paling dominan berhubungan dengan kadar LDL, dengan OR sebesar 2,793 dibandingkan dengan beberapa variabel lainnya (Sukatemin, 2013).

Hasil penelitian ini mendapatkan bahwa 59 responden berdasarkan dari kelompok indeks massa tubuh yang berlebih > 25 sebanyak 17 orang dengan persentase $68 \%$ dan orang yang non obesitas $<24$ sebanyak 13 orang $17,3 \%$ ini adalah yang kadar LDL nya lebih dari normal $>200 \mathrm{mg} / \mathrm{dL}$ yang artinya dari 59 responden yang termasuk dikatakan tinggi $50 \%$ meningkat kadar LDL nya. Hasil uji Chi Square didapat nilai $p>a \quad 0,024<$ 0,05 . Artinya $\mathrm{Ha}$ diterima dapat disimpulkan secara statistik terdapat kemaknaan antara indeks massa tubuh dengan kadar LDL pada penderita diabetes melitus tipe 2. Dan Ho tidak dapat di terima dengan artian tidak ada hubungan.

Untuk peneliti sendiri mendapatkan bahwa hasil orang yang memiliki indeks massa tubuhnya berlebih $>25$, memiliki peluang 3.433 kali beresiko untuk meningkatnya kadar LDL dan mengakibatkan terjadinya faktor risiko diabetes melitus tipe II dibandingkan dengan orang yang indeks massa tubuhnya normal $<25$.

Hasil penelitian ini sejalan dengan penelitian Koampa dkk (2016) tentang hubungan antara indeks massa tubuh dengan kadar profil lipid pada pasien diabetes melitus tipe II. Dan hasil berdasarkan statistik yang peneliti dapatkan bahwa hasil uji statistiknya adalah yang artinya pada obesitas ini memiliki peluang 3,433 kali lebih beresiko untuk meningkatnya kadar LDL dan beresiko jatuh ke kondisi diabetes melitus tipe II (Koampa dkk, 2016). 


\section{KESIMPULAN}

Terdapat hubungan antara indeks massa tubuh dengan kadar LDL pada penderita diabetes melitus tipe II FTKP di praktek mandiri Dokter Hakikiyah Lampung Tengah Tahun 2019.

\section{Daftar Pustaka}

IDF. 2015. International Diabetes Federation Atlas 6th. htp://www. idf.

Hata, J. \& Kiyohara, Y. 2013. Epidemiology of stroke and coronary artery disease in Asia. Circulation Journal, pp.CJ13.

Hasan CMM, Parial R, Islam M, Kasru A. Association of hba1c, creatinine and lipid profile in patients with diabetes mellitus. J Middle-East of Scientific

Research.2013;16(11):1508-11. 12

Hussain, A. \& Ali, I. Kaleem, W.A. \& Yasmeen, F. 2019. Correlation between Body Mass Index and Lipid Profile in patients with Type 2 Diabetes attending a tertiary care hospital in Peshawar. Pakistan journal of medical sciences, 35(3), p.591.Tersedia dari : https://scholar.google.com/schola $r ? \mathrm{hl}=$ en\&as_sdt $=0 \% 2 \mathrm{C} 5 \& \mathrm{q}=$ Corre lation+between+Body+Mass+Ind ex+and+Lipid+Profile+in+patient s+with+Type+2+Diabetes+attend ing $+a+$ tertiary+care+hospital+in +Peshawar\&btnG=

PERKENI. 2015. Perkumpulan Endokrinologi Indonesia. Pengelolaan dan pencegahan diabetes melitus tipe 2 di Indonesia. Pb. Perkeni.

Kemenkes. 2014. Pusat Data dan Informasi Kementerian.

Kemenkes. 2014. Hipertensi. Jakarta Selatan: Pusat Data dan Informasi Kemenkes RI.

Koampa, P.H., \& Pandelaki, K. \& Wongkar, M.C. 2016. Hubungan indeks massa tubuh dengan profil lipid pada pasien diabetes melitus

tipe 2. e-CliniC, 4(1).

Longmore \& Murray. 2014. Buku Saku Oxfort Kedokteran Klinis. Edisi 8, Jakarta. EGC.

Notoatmodjo. 2012. Metodologi Penelitian Kesehatan. Jakarta: PT Rineka Cipta.

Sukatemin. 2013. Kajian hubungan nilai hba1c, hiperglikemia, dislipidemia dan status vaskuler (berdasarkan pemeriksaan ankle brachial index/abi). Jurnal Universitas Muhammadiyah Yogyakarta, Yogyakarta, 7(1), hh. 50-55.

Waspadji, S. 2007. Diabetes Melitus: Penyulit Kronik dan Pencegahannya. Dalam: Penatalaksanaan Diabetes Melitus Terpadu. Jakarta: Balai Penerbit Fakultas Kedokteran Universitas Indonesia.

WHO. 2017. World Health Organization [updated 2017; cited 2017 July 11]. Tersedia from http://www.who.int/topics/diabet es mellitus/en/. 